\title{
A Conceptual Framework for Unified 3D Digital Management of Urban Land and Property Information
}

\author{
Abbas Rajabirad, Jihye Shin, Behnam Atazadeh and Mohsen Kalantari \\ University of Melbourne, Australia
}

\begin{abstract}
Over recent years, unprecedented urbanization has fostered the rapid development of multi-storey buildings and infrastructure facilities, resulting in spatial and functional complexities in cities. Land and property information plays a vital role in a wide range of applications in land administration in rapidly growing cities. However, the current fragmented practice relying on 2D representation does not provide a reliable and accurate legal description of underground and aboveground properties as a foundation for evidence-based decisions in support of economic prosperity, human activities and public safety in urban areas. We propose a conceptual framework for 3D digital management of urban land and property information. The framework provides a foundation to federate various 3D models, validate their integrity, and analyse them for land administration. Using a case study of a multi-owned building located in the state of Victoria, Australia, this paper explores the practicality of the framework to support decision-making in building subdivision.
\end{abstract}

\section{Keywords:}

land and property information, map base, 3D SDI, 3D digital data, 3D data validation

\section{Introduction}

Rapid urbanization and population growth have led to high pressure on vertical development and land use in urban areas around the world, resulting in spatial complexities associated with the legal ownership of properties. Urban land and property information refers to the legal ownership of all properties on the Earth's surface or of underground facilities/infrastructures. This information specifies the legal entitlements to carry out activities within an urban community at the individual, group and public levels. It plays an important role in managing our rapidly growing cities to accommodate the increasing population, as well as in supporting a wide range of applications in land administration, such as positioning, navigation, transportation and urban planning.

Most governments provide map bases as an enabling infrastructure for decision-making at various levels across government, businesses and communities. Map bases are the authoritative graphical representations of land parcels. In general, their $2 \mathrm{D}$ representation omits an array of 
physical property objects that are vertically located, such as apartment blocks, tunnels, and underground utility networks. The current silo-based approach for managing and planning urban information is inadequate for reliable and accurate legal descriptions of underground and aboveground properties (Tsiliakou, Labropoulos, \& Dimopoulou, 2013), and for supporting decision-making in managing vertical living environments and planning other aspects of urban settings.

A 3D digital data framework for urban land and property will be fundamental for evidencebased decisions concerning economic prosperity, human activities and public safety in cities (Stoter et al., 2011). Such a framework can support urban planning and the management of infrastructure assets, as well as such things as drilling for oil and forecasting the impacts of a flood. The benefits derived from moving to a 3D digital approach have been noted at government, society and industry levels as follows: (1) improving the authority's ability to make decisions in urban planning and development; (2) reducing disputes within multi-owned buildings $(\mathrm{MOB})$ through facilitating a clear understanding of the 3D extent of ownership; and (3) enhancing productivity by exchanging 3D data for asset management with high interoperability (Acil Allen Consulting, 2017). The estimates indicate that a 3D data infrastructure will provide 2.1 billion Australian dollars of economic benefit for Australia over the next 20 years (Acil Allen Consulting, 2017).

Some jurisdictions have implemented a 3D digital data framework for urban land and property for specific purposes. However, a knowledge base to establish the framework for modernizing land administration practices is generally lacking (Stoter et al., 2011). This research aims to explicate critical components for implementing a $3 \mathrm{D}$ data framework to facilitate the integrated management of land and property in urban areas. Because the legal foundation for managing land and property information varies between countries, this paper focuses on a specific jurisdiction - the state of Victoria, Australia. The case study of an MOB located in Victoria was conducted to demonstrate the practicality of the suggested framework to support decisionmaking in building subdivision.

\section{Management of Urban Land and Property Information}

\subsection{Challenges}

Land administration practices refer to the information and processes required for supporting the subdivision, registration and ongoing management of rights, restrictions, and responsibilities (RRRs) associated with land and vertically arranged properties (Ho, Rajabifard, \& Kalantari, 2015). Although practices differ between jurisdictions, 2D map bases are typically used to describe the spatial extent of land and properties (see Figure 1). Most countries, including Australia, now give ownership titles for properties within MOBs using the same 2Dbased methods developed for traditional broadacre development on vacant land. Moreover, the spatial dimensions of urban land and properties located above and below the earth's surface are not represented in the property map bases of most jurisdictions around the globe. 


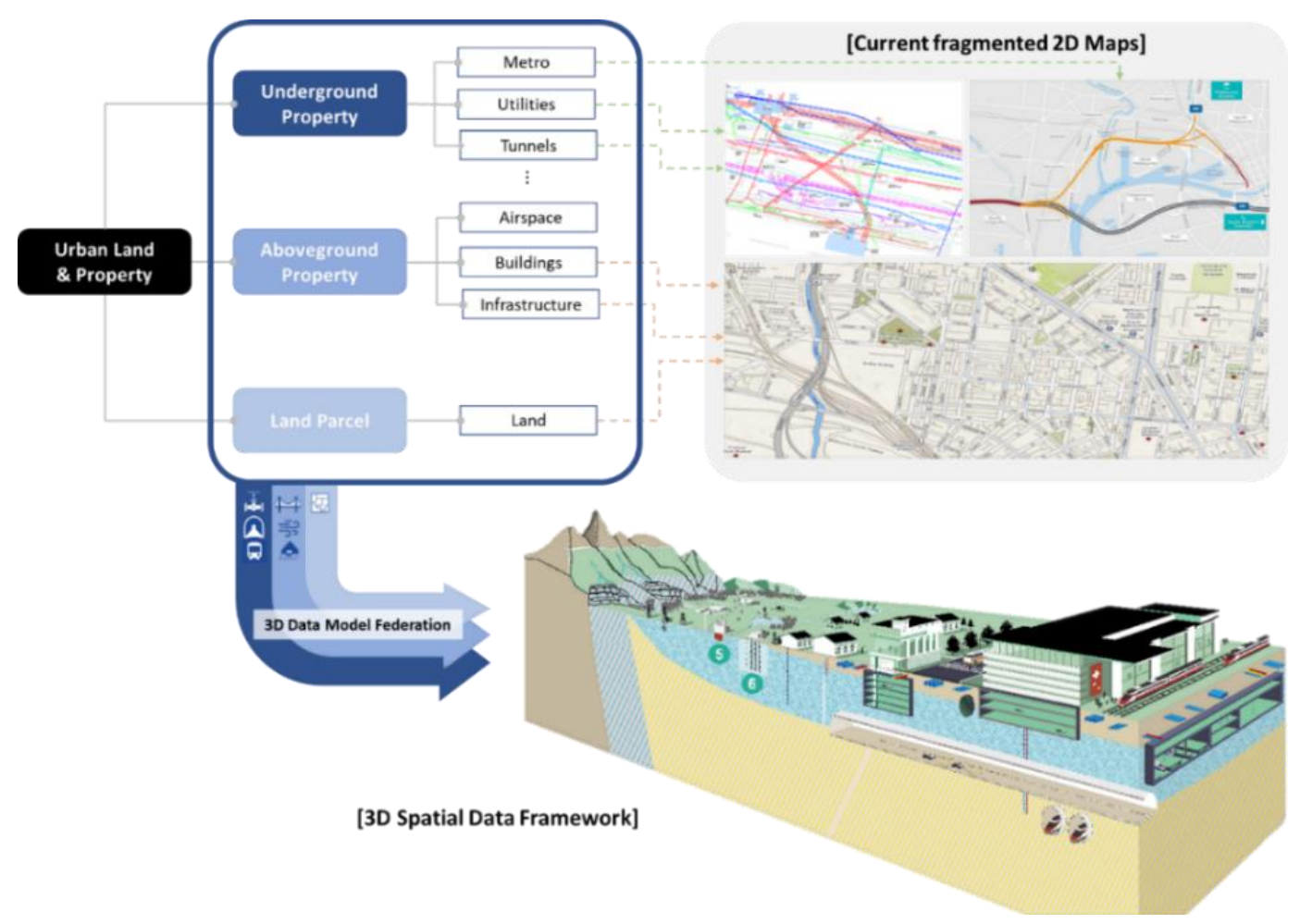

Figure 1: A diagrammatic representation of the complexity of urban land and property

The 2D map base of the state of Victoria provides only the name of a multi-owned property located on a land parcel. The plan of subdivision (the cadastral plan in Victoria) describes the 3D spatial extent of ownership RRRs of multiple properties within one parcel using 2D projection (floor plan and cross-section diagrams). This plan cannot sufficiently delineate the complicated arrangement of multi-layered 3D legal spaces and their ownership RRRs in structurally complex multi-owned properties. According to earlier research, a 40-storey building in Melbourne requires a plan running to 60 pages to show the 3D spatial extent of ownership RRRs (Rajabifard et al., 2014). It is highly unlikely that anyone from outside the surveying profession would be able to interpret the land and property information in the plans correctly by knitting all plan drawings together.

To overcome the challenges in managing land and property information using a 2D-based practice, communicating information about urban environments is no longer limited to 2D maps (Atazadeh, Rajabifard, Kalantari, \& Shin, 2018). However, international initiatives to develop a 3D-based cadastre mainly address 3D visualization and 3D data models for specific aspects of land administration. Little attention has been paid to creating a more comprehensive and holistic approach to support the variety of decision-making in land administration in the 3D data environment. 


\subsection{D Data Models in the Land Administration Domain}

Several jurisdictions, including Sweden, Norway and the Australian states of Victoria and Queensland, have examined and implemented prototype 3D cadastres as systems for the comprehensive documentation of land and property information (Shojaei et al., 2017). In the trend towards 3D cadastres, there has been an effort to establish 3D digital models that provide comprehensive representations of complex built structures located vertically, both above and below the ground (Zhu, Hu, Zhang, \& Du, 2009). Rajabifard, Atazadeh and Kalantari (2018) categorize 3D data models in the land and property development domain into three types: purely legal, purely physical, and integrated models.

Purely legal 3D models focus solely on legal spaces to manage land and property information in a 3D digital environment. LADM at an international level and ePlan in Australia are two of just a handful of legal models that are able to support 3D legal objects. Legal models are adequate for registering ownership RRRs of land and properties, but they have limitations in communicating the legal ownership allocated within the complicated physical structures of multi-owned properties.

Purely physical models focus mainly on the 3D physical representation of built assets with limitations in managing legal information. There are three dominant physical models: CityGML and IndoorGML for the geospatial industry, and IFC for the building sector. Although those models are adapted for managing existing physical aspects of urban built environments, they can be extended to incorporate further information for managing urban land and property. For example, the potential of IFC, a standard data structure for building information models (BIM), to be extended to accommodate the legal information has been explored in several studies (Atazadeh, Rajabifard, \& Kalantari, 2017; Rönsdorff, Wilson, \& Stoter, 2014).

Integrated information models have recently emerged due to the need to link the legal and physical dimensions of properties that have multiple owners such as MOBs. Different integrations of physical and legal models have been considered at a conceptual level, such as the integration of CityGML and LADM (Rönsdorff et al., 2014). The 3D data models all show very limited legal aspects of land and property (such as boundary location and type). 3D models are yet to be developed that support land and property management practices fully.

\subsection{D Spatial Data Integrity and Validation for Urban Land and Property}

Decision-making in land administration relies on a wide variety of legal objects, from 2D entities like land parcels to complex 3D objects for MOBs. To guarantee the quality of the results of the decisions, the diverse data associated with legal spatial objects must be trustworthy and contain the required detail (Thompson \& Van Oosterom, 2012). This implies the need to develop 3D spatial data validation rules to ensure the spatial integrity of volumetric legal spaces in urban environments. Validation is the process of checking whether consistency, integrity, correctness and completeness of data can be guaranteed before the data is processed or entered into the system (Karki, Thompson, \& McDougall, 2010). Despite the existence of a wide range of (2D) validation rules, the complete manual validation of $3 \mathrm{D}$ cadastral data is an almost impossible task (Drobež, Fras, Ferlan, \& Lisec, 2017). Moreover, the current 2D 
validation rules are not fully capable of ensuring an unambiguous and definitive spatial and legal definition of 3D property parcels.

Research into the validation of 3D data has been concerned mainly with spatial aspects, such as six types of 3D validation for geometry (Karki et al., 2010), geometric validity axioms for LADM (Thompson \& Van Oosterom, 2012), and a set of validation rules for the complete set of 3D geometric primitives (Kazar, Kothuri, Van Oosterom, \& Ravada, 2008). This research has centred primarily on providing a general mathematical definition of validation checks for 3D objects. Although some fundamental concepts have been identified, synthesizing the research in line with a cadastral system is essential to ensure that 3D cadastral data can be guaranteed through a set of validation rules and a valid examination process.

\section{Framework for 3D Digital Management of Urban Land and Property Information}

Building a 3D digital data infrastructure for urban land and property information is achieved by applying a four-stage conceptual framework: modelling, federation, validation and analytics (see Figure 2).

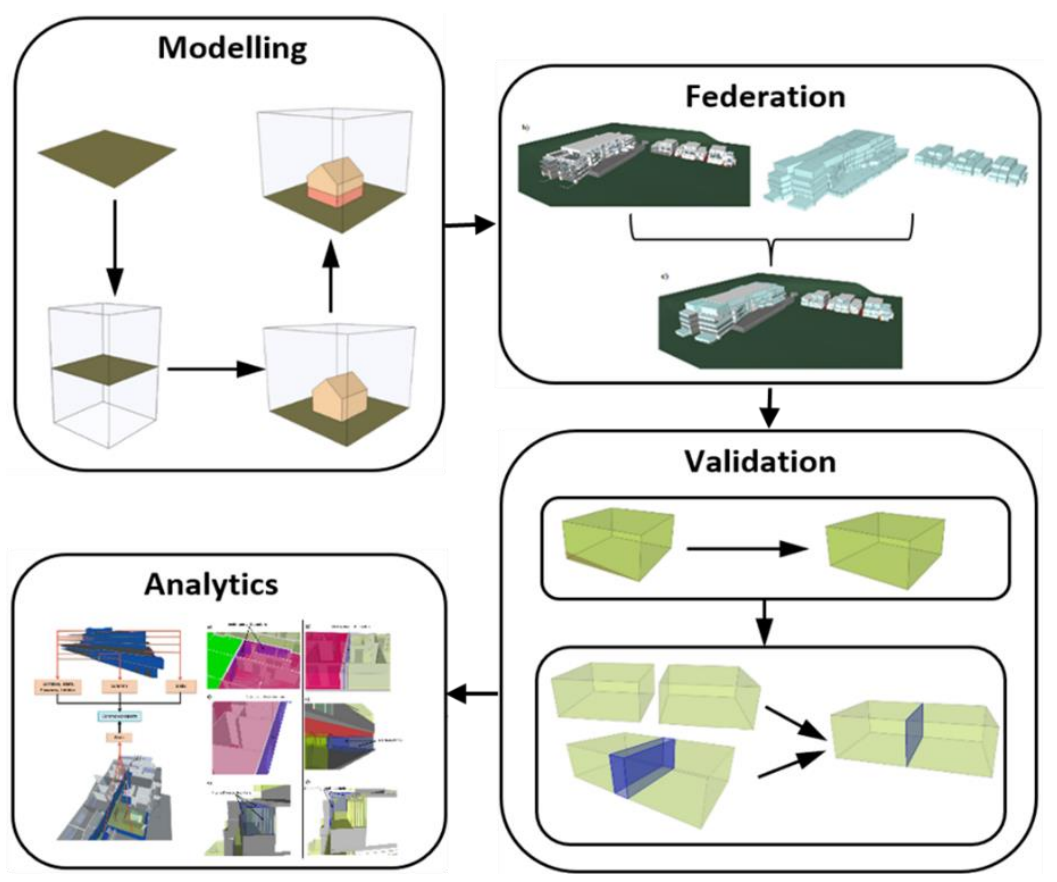

Figure 2: A conceptual framework for 3D urban land and property management 


\subsection{Modelling}

Modelling urban land and property in a 3D digital environment requires different levels of detail for various parts of cities. The legal boundaries of land parcels (horizontal extent of ownership of land parcels) and their height and depth ownership extent (vertical extent of ownership of land parcels) are adequate in suburban areas where one land parcel belongs to one person. On the other hand, in city areas, a detailed model showing the complex ownership arrangements both indoors and outdoors of multi-owned properties is required. Three levels of complexity for urban land and properties are suggested: (1) land parcels without any built property; (2) land parcels with their height and depth extents; and (3) land parcels with individually owned under- and above-ground properties (see Figure 3). The individually owned properties located above ground and underground include single-owned properties as well as multi-owned properties. 3D models of land and property can be sourced from the standard data models referred to in section 2.2. Connecting two physical models, for buildings (IFC) and for a city as a whole (CityGML), provides highly detailed physical information about urban built environments (Zhu et al., 2009). As explained above, unless they are extended these physical models are unable to accommodate the legal ownership of private, communal and public properties within urban areas. Therefore, another innovative aspect of this project is to identify a good mechanism for extending these data models to incorporate the legal ownership information.

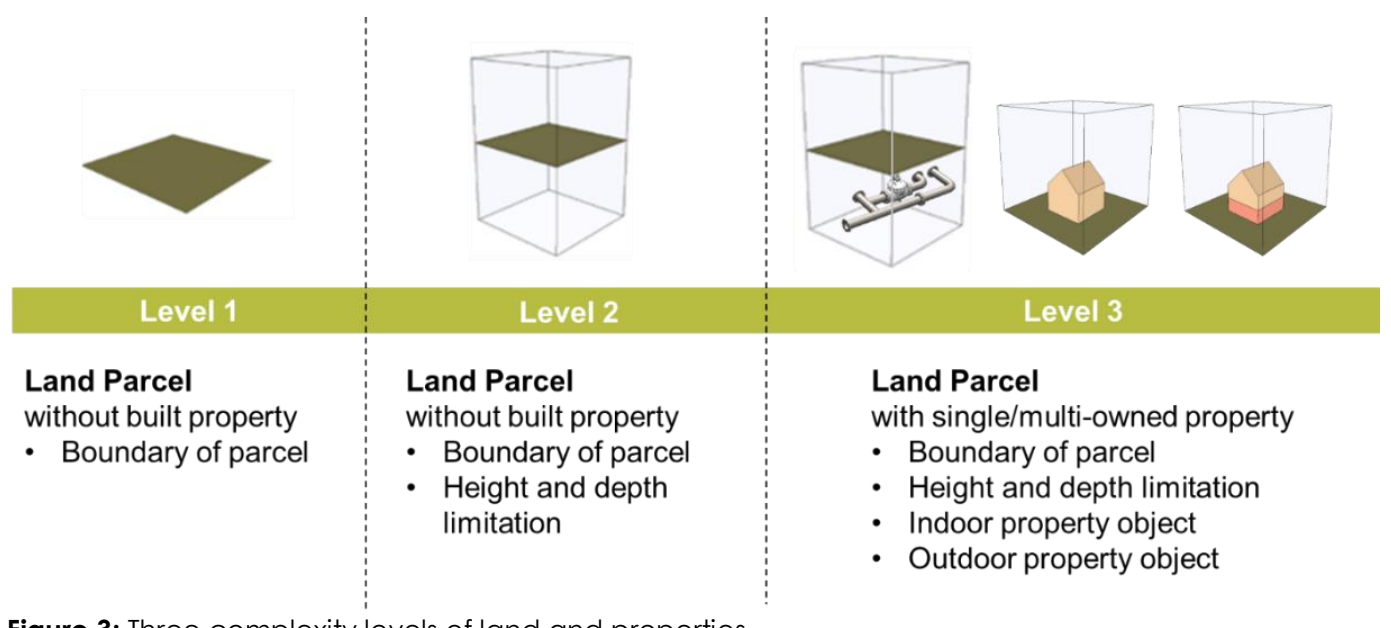

Figure 3: Three complexity levels of land and properties

As noted by Volk, Stengel and Schultmann (2014), physical aspects of the 3D model can be captured in two ways, as represented in Figure 4. For newly built properties, expanded physical models for the legal aspect are typically defined by 3D data authoring tools. The critical components in the management of legal information of multi-owned properties, such as type and location of legal boundaries, or spatial arrangements of legal interest, can be presented well in the IFC model (Atazadeh, Kalantari, Rajabifard, Ho, \& Champion, 2017). In the case of existing urban properties, a reverse-engineering approach for generating 3D models needs to be adopted to create the as-built reality of the properties. This semi-automatic approach 
generates the 3D geometry of a property according to the points-to-BIM transformation process, which consists of data capture, data processing and BIM creation. Within the process, point clouds captured by laser scanners are coordinated and integrated as one. This integrated point cloud can then be used to guide the generation of geometry in BIM authoring tools. This corresponds to the expanded IFC data schema. During the BIM creation phase, the legal information for a property is defined and overlaid with physical elements (spaces and building elements) of the IFC model.

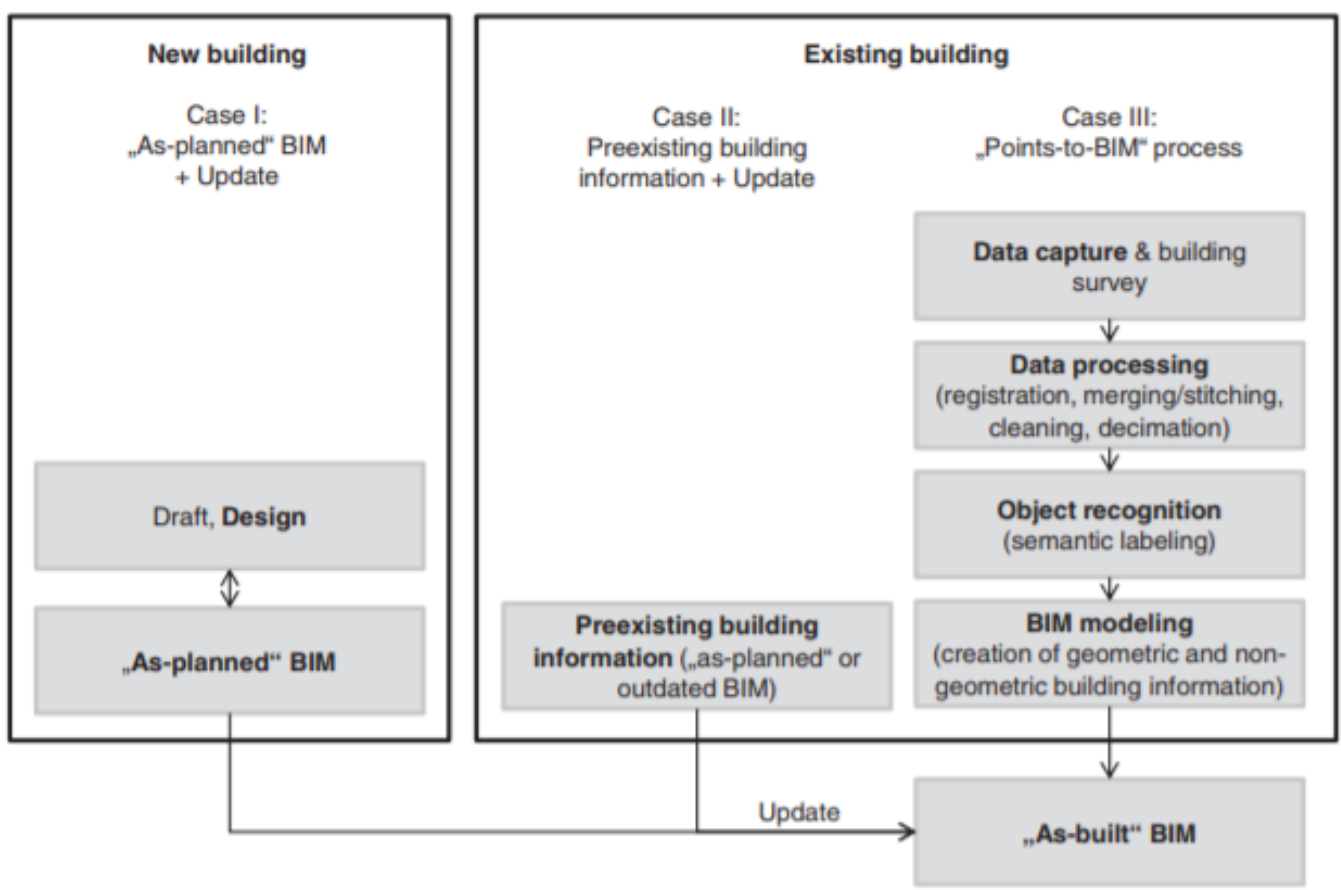

Figure 4: The BIM-centred process for generating a 3D physical model (adapted from Volk et al., 2014)

\subsection{Federation}

As discussed in section 3.1, not every part of a city needs the same level of detail in a 3D land and property model. In line with this, different mechanisms for federating $3 \mathrm{D}$ models are needed to combine the information at the appropriate level of detail. This research proposes the following four-stage process for 3D data federation: stage 1: legal space definition for all land parcels giving height and depth limits; stage 2: physical information and 3D legal spaces in multi-owned properties; stage 3: 3D outdoor legal spaces and 3D utility networks; stage 4: 3D digital visualization (see Figure 5). 


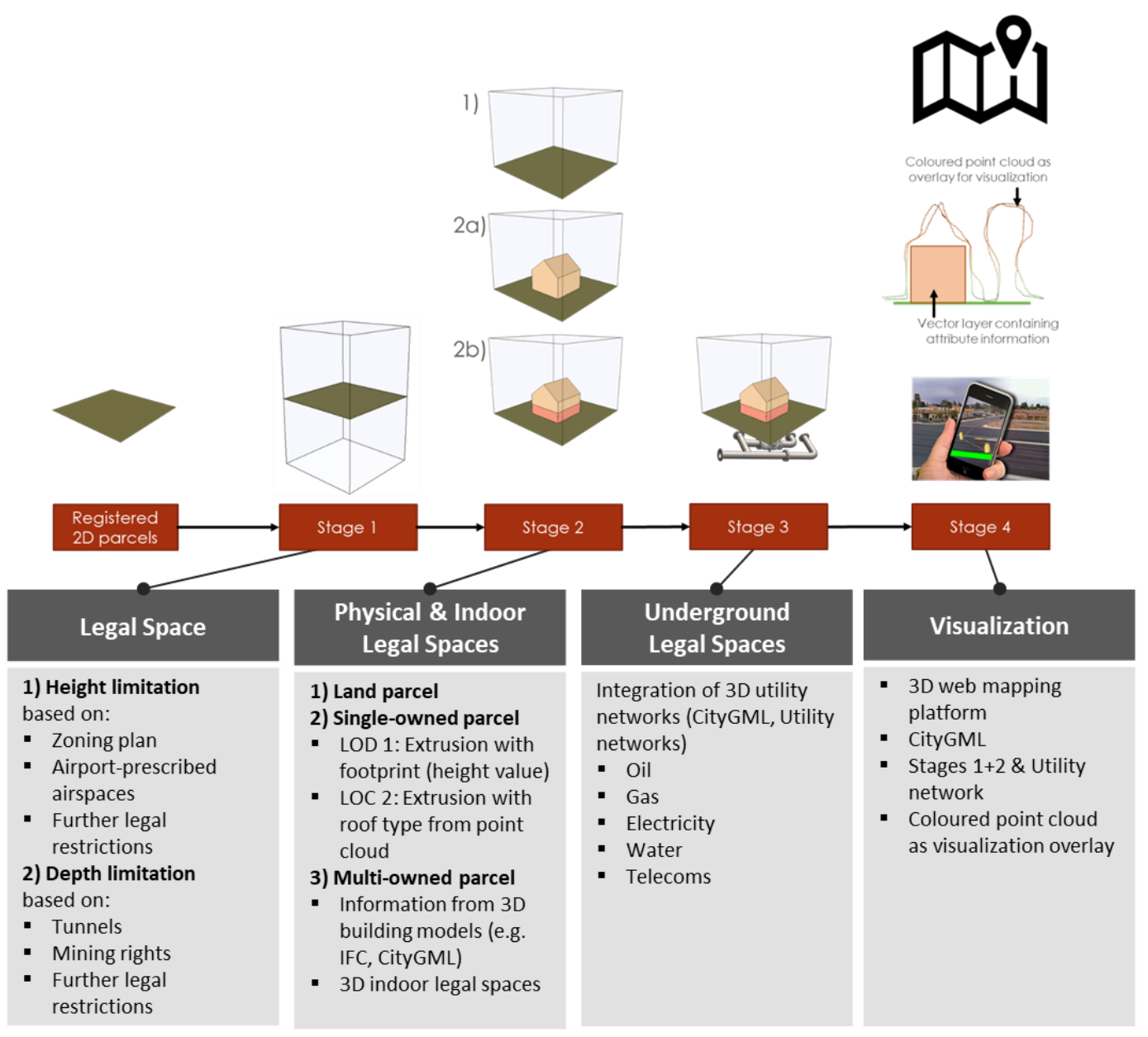

Figure 5: The suggested process for federating various 3D digital models

The federation of 3D digital models requires the integration of indoor and outdoor property objects. These comprise both physical elements and legal spaces. The physical components in the integrated model can be obtained from IFC and CityGML (Rajabifard et al., 2018). Physical elements inside buildings can be defined based on IFC, since this 3D digital model allows the modelling of architectural, structural and utility elements within buildings. CityGML entities can be used for modelling other urban structures, such as tunnels, bridges and roads. The legal elements of the federated model can be defined in the IFC model by extending its data structure. Finally, the federated 3D model is implemented in a platform-independent 3D digital environment to facilitate visual communication of complex arrangements of urban land and property. 


\subsection{Validation}

Trustworthy 3D data is fundamental for any decision related to land and property management. Therefore, 3D data for urban land and property should be validated in order to create meaningful 3D legal objects. In the jurisdiction area of Victoria, 128 validation rules (112 non-spatial and 18 spatial rules) were applied to evaluate the data quality of 2D-based ePlan models for the land registry system (Shojaei et al., 2017) (see Table 1). The non-spatial rules are essential to check textual administrative information. Among the spatial rules, geometric rules are used to examine depth and height boundaries of legal space (lot, common property and easement). In addition, spatial connectivity ensures the intrinsic connectivity within legal property objects, as well as extrinsic connectivity of one object with others. Intrinsic rules help to produce valid geometries of individual objects, while extrinsic rules ensure that there is no gap or overlap between any two objects across the whole urban area.

Table 1: Extract from 2D ePlan validation rules (adapted from Shojaei et al., 2017)

\begin{tabular}{c|l|c|l}
\hline \multicolumn{1}{|c|}{ Semantic Rule } & \multicolumn{1}{c}{ Geometrical Rule } \\
\hline No. & \multicolumn{1}{c|}{ Rule } & No. & \multicolumn{1}{c}{ Rule } \\
\hline VR005 & Easement Purpose Exists & VR063 & Parcel Area \\
VR006 & Owners Corporation Limitation Exists & VR069 & Parcel Geometry Closure \\
VR008 & Road Parcel Description Exists & VR072 & Title Boundary Consistency \\
VR019 & Title Reference & VR073 & Title Connection \\
VR034 & Depth Limitation Manual Check & VR074 & Survey Marks Connection \\
VR047 & Easement Benefit & VR084 & Restriction Fixing \\
VR062 & Existing Crown Parcels & VR106 & Easement Width \\
VR104 & Building Boundary Description & VR117 & Overlapping Parcels \\
\hline
\end{tabular}

Like ePlan rules, the $2 \mathrm{D}$ validation rules based on the relevant legislation can be leveraged to develop $3 \mathrm{D}$ validation rules for land and property information. According to the specific landadministration purposes, a variety of $3 \mathrm{D}$ validation rules can be developed to examine the quality of 3D data for land and property. In this section, $2 \mathrm{D}$ ePlan validation rules, which are the typical checking-rules for the urban land and property information in practice, are used to exemplify the transformation to $3 \mathrm{D}$ rules.

The non-spatial rules for the ePlan model can be directly translated into checking-rules for the IFC model in order to examine its semantic information regarding legal ownership. However, spatial rules need to be revised based on the 3D volumetric shape of legal objects. Two ePlan rules, VR104 - Building Boundary Description and VR117 - Overlapping Parcels, serve as examples in this section to explain how validation rules examine the expanded IFC model of an MOB (see Figure 6). VR104 for examining whether each legal boundary within a building is described can be applied to IFC models. This rule checks the building boundary types of the building elements, representing the location of boundaries in an IFC model. In addition, VR063, which relates to checking whether parcels overlap, can be implemented for IFC models by checking whether the 3D extent of a legal space touches the surface of any other space. 


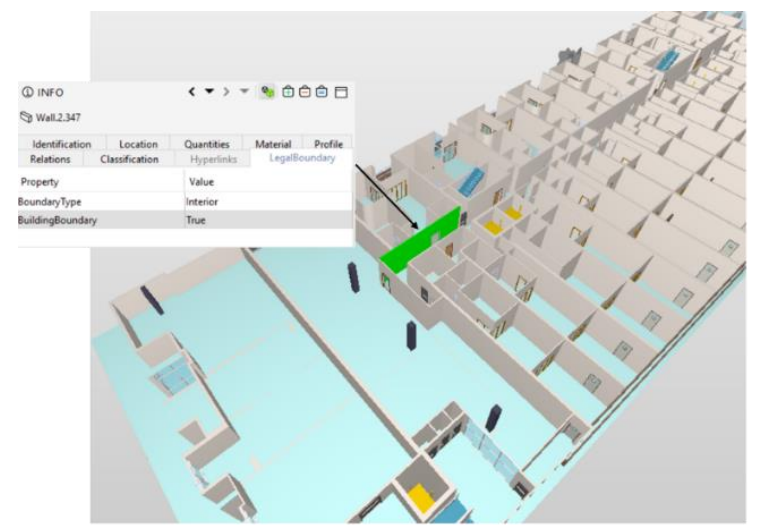

(a) Validation of an IFC model on Rule VR104-Building Boundary Description

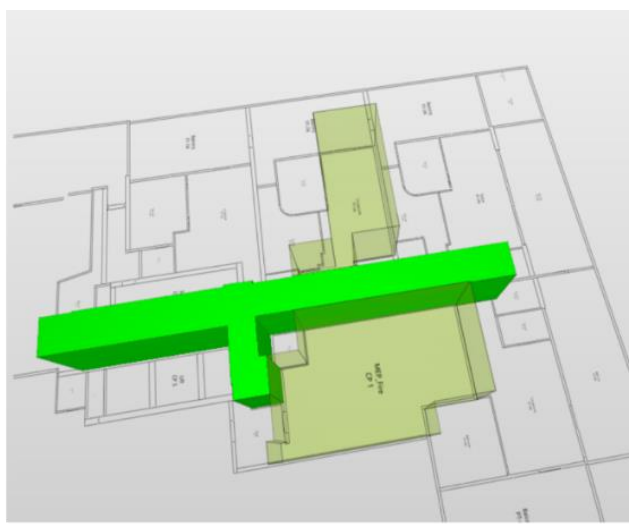

(b) Validation of an IFC model on Rule VR117-Overlapping Parcels

Figure 6: Application of ePlan validation rules to a 3D data model

\subsection{Analytics}

Informed decision-making regarding land and property management needs to draw on a broad analysis base in the architecture, urban planning and land administration domains. Currently, the generation of $3 \mathrm{D}$ analysis models with different levels and types of information for each of these areas is a time-consuming and error-prone manual process and a key barrier to conducting 3D data analytics. 3D data query potentially supports the automatic generation of an input data model for each analysis from one federated model, as represented in Figure 7. The federated model of indoor, outdoor, physical and legal data for land and property functions as a central repository of land and property information.

3D land and property analytics have new implications for decision-making in complex urban built environments (Rajabifard et al., 2018), enabling property information to be leveraged for new urban applications, such as estimating the density of occupancy in 3D indoor spaces. In addition, volumetric computation of urban land and legal property spaces will be possible for the valuation of individual properties within complex developments. Another 3D analytics capability will be performing a 3D buffer analysis to identify under- and above-ground properties affected by new urban development. Therefore, 3D spatial data analytics will add valuable knowledge for making decisions associated with the legal ownership of land and property in complex densified urban areas. 


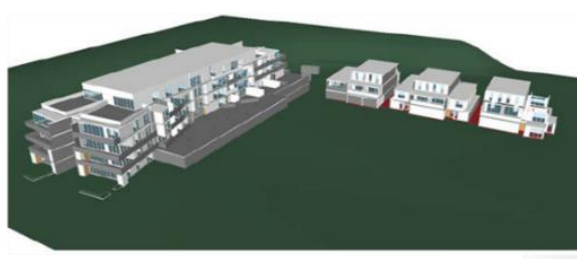

Federated 3D Model

Indoor, outdoor, physical and legal data

for land \& property management
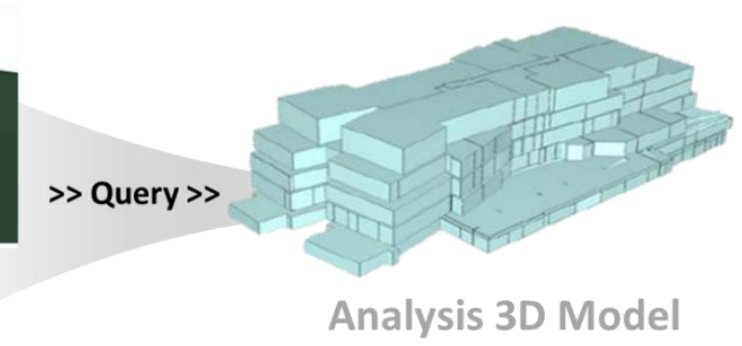

Input data model for specific analysis for land \& property management

Figure 7: Automatic generation of a 3D input model from the federated 3D model for use in land and property management (adapted from (Atazadeh, Rajabifard, et al., 2017)

\section{Application of the Proposed Framework to Case Study}

In this section, the practicality of the suggested conceptual framework is discussed in relation to a particular scenario - examination of ownership allocation within an MOB. A crucial practice in land administration, unreasonable partitioning of legal ownership extent in MOBs has generated increasing numbers of disputes over the use and management of properties (Shin, Rajabifard, Kalantari, \& Atazadeh, 2019). The framework is applied to a case study building, a 24-storey MOB located in Melbourne. Autodesk Revit 2016 was utilised to generate an IFC model of the property. The federation, validation and analytics were conducted using Solibri Model Checker (SMC), an IFC rules-based model-checking tool.

Firstly, the IFC data structure was extended to accommodate the legal aspect of the MOB described in the plan of subdivision. The five building structures (wall, floor, ceiling, window and door), which are referred to as building boundaries in subdivision plans, are matched to sub-entities of 'IfcBuildingElement' (see Figure 8). To accommodate additional information regarding legal information, the data schema for each entity is extended using IfcPropertySet. In this extended data structure, IFC entities representing the five building structures used as building boundaries include two further attributes (BuildingBoundary and BoundaryType) as attributes newly defined by users.

Based on the IFC extension, the physical aspect (arrangement of building elements with boundary-type information) and legal aspect (layout of legal spaces and location of building boundaries) of the two storeys of the MOB are generated in Revit and exported individually as IFC data. 


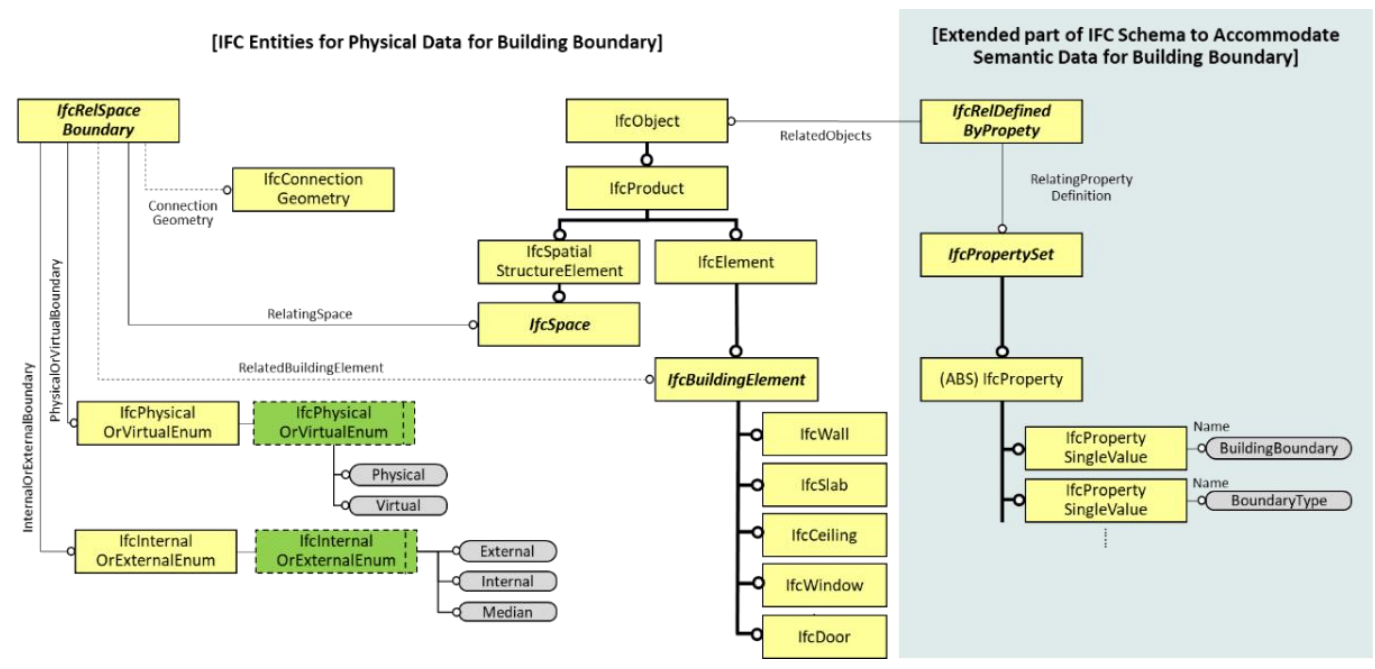

Figure 8: The Extended Part of the IFC Data Structure, allowing the Legal Information for the Scenario Examination of Ownership Allocation within an MOB - to be accommodated

Using SMC, the two IFC models are federated into one. Figure 9 illustrates part of the federated IFC model - a green-coloured legal space representing a corridor (a part of common property) overlapped with building elements, including a boundary wall, which has two extended properties (i.e. BuildingBoundary and BoundaryType). The following ePlan validation rules that should be checked before analytics for the scenario were translated into an SMC rule-set: VR072 - Title Boundary Consistency, VR100 - Building Boundary Annotation and VR104 - Building Boundary Description. Using the template rule 'Property Rule Template with Component Filters Rule', three SMC rules to check the semantic information related to ePlan rules were defined. In the SMC rule for VR104, for instance, a building boundary description is examined by checking the 'Boundary'Type' properties for five types of building boundary structure that have a 'True' 'BuildingBoundary' property (see Figure 9). 


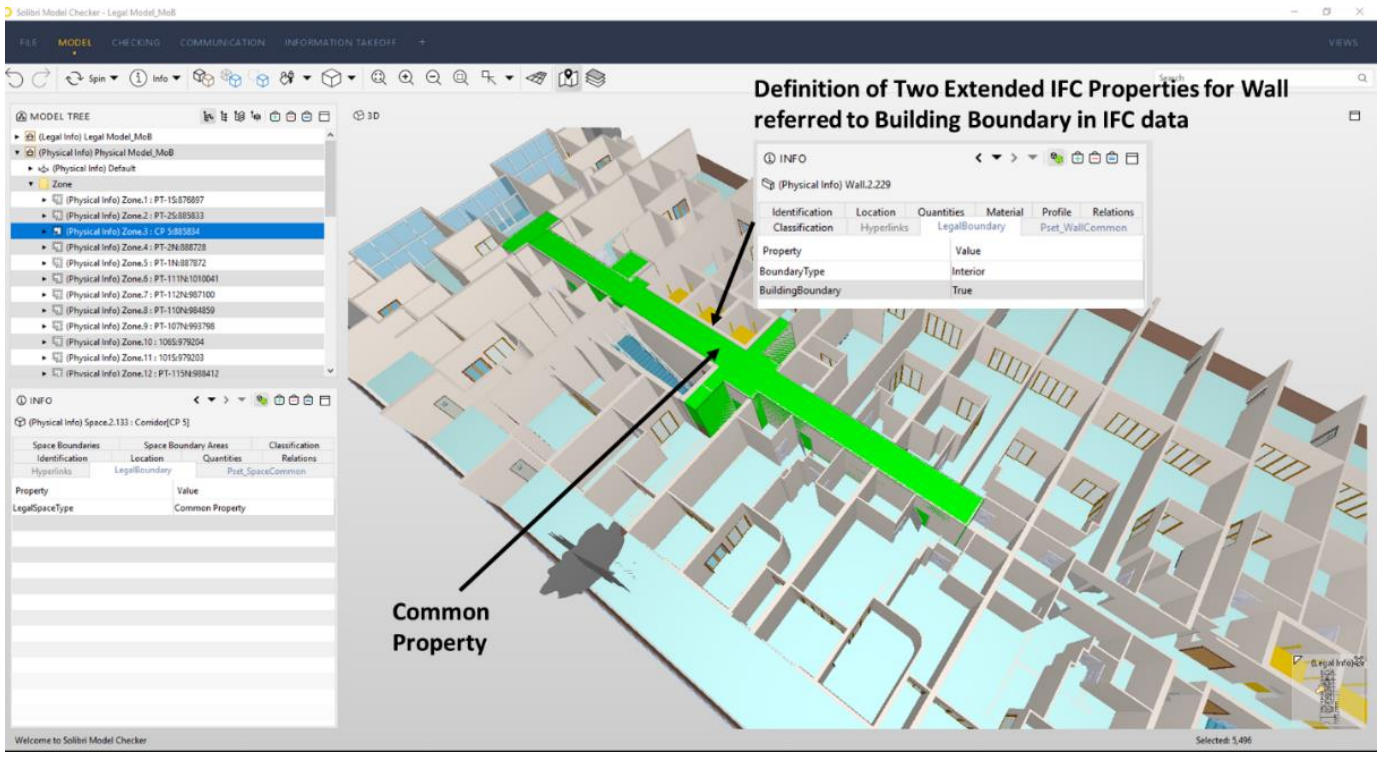

Figure 9: The Two Federated IFC Models of the Case Study MOB (Physical and Legal IFC models).

In building subdivision practice, two principles for good ownership allocation are (1) defining 'median' building boundaries between two lots, and (2) defining 'interior' building boundaries between lot and common property. For VR072, the consistency of the ownership partitioning can be analysed according to the same principles as those which can be translated into the $\mathrm{SMC}$ rules. In the same manner as for validation, the template rule 'Comparison Between Property Values' was used to translate two principles into SMC rules (see Figure 10). For example, the compliance of an IFC model with principle (2) is determined by filtering the building elements for interior 'Boundary'Type' and checking that these components touch the surface of two spaces defined as lot and common property. Within SMC, the data query for analytics was well executed by setting the data filter, and the analytics for the scenario was conducted successfully using two rules. As illustrated in Figure 11, the results showed that the tested IFC model was compliant with the two principles. 


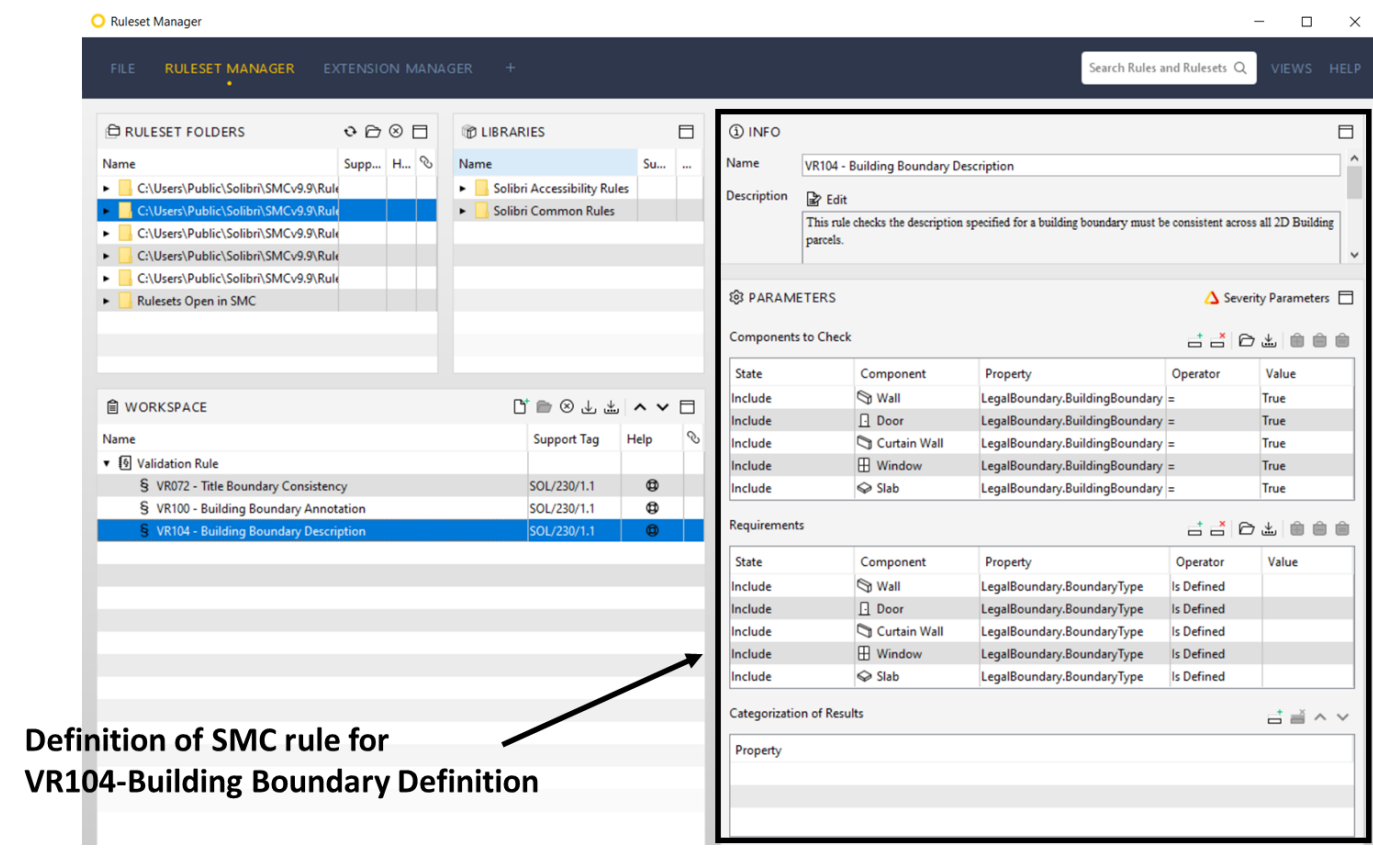

Figure 10: The Defined SMC Rule for ePlan Validation - VR 104-Building Boundary Definition

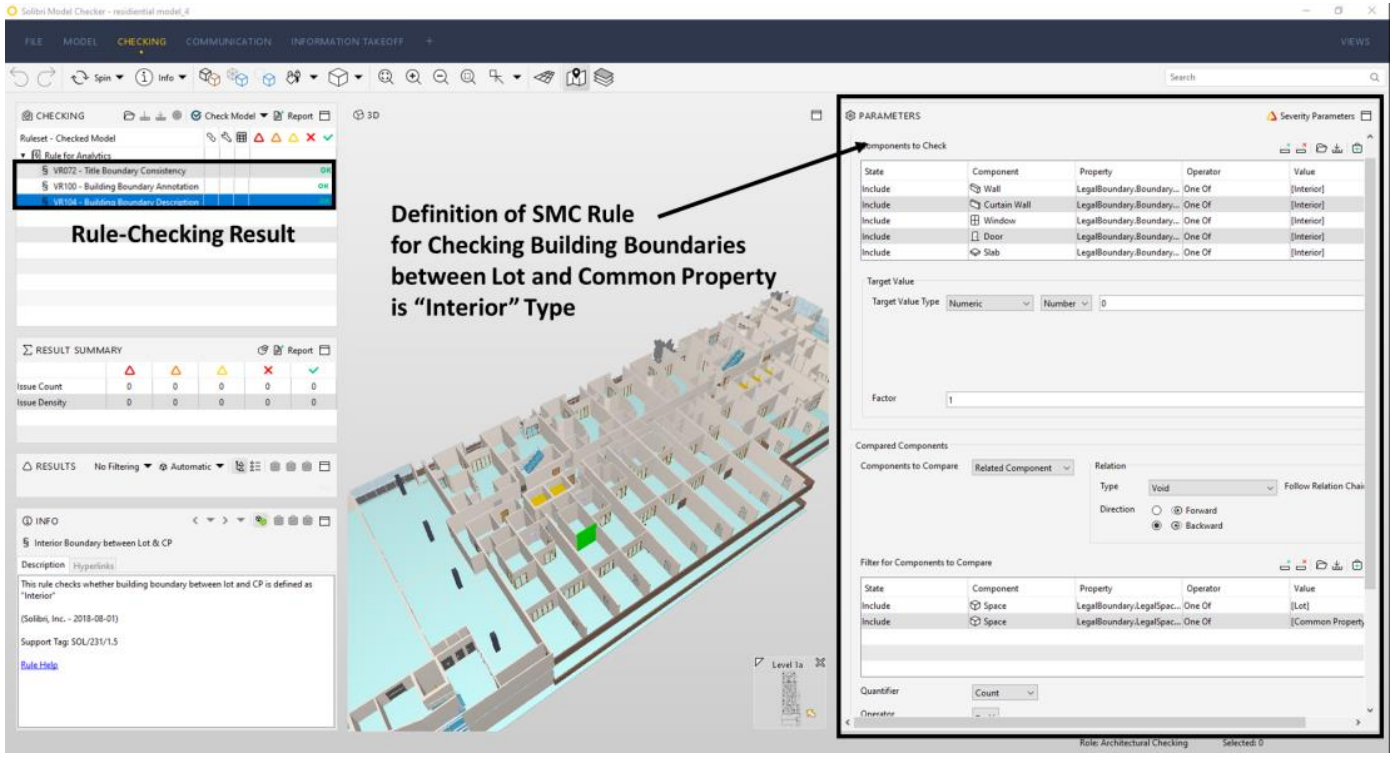

Figure 11: The Result of Validating the IFC Model based on Three SMC Rules - VR072, VR100 and VR104 


\section{Discussion}

Current 2D-based practice in land administration is based on the fragmented approach for recording, sharing and using information on urban land and property. This results in challenges for effective decision-making related to management and operation of urban environments. Moving towards a 3D-based approach, this paper has suggested a conceptual framework for 3D digital management of land and property information in urban areas. In this framework, information required for specific analyses in planning and managing cities can be acquired from the federated 3D digital data models for land and property information. The federated model has high integrity, achieved through validation using spatial queries. As a basis for informed decision-making, the framework can facilitate the visual communication of the full extent of legal and physical indoor and outdoor properties to various stakeholders (e.g., owners, city councils, utility companies and land registries).

In the case study, two IFC models for physical and legal aspects of an MOB were created and federated into a single model. In addition, validation and analysis of the integrated IFC model for ownership allocation within an $\mathrm{MOB}$ were executed based on the $3 \mathrm{D}$ data validation rules, IFC data query, and analysis methods in SMC. The case study shows the potential of the framework presented here to support decision-making in land administration by supporting the creation, exchange, utilization and management of urban land and property information systematically. Our results show that adopting IFC, an international open standard, provides high interoperability throughout the whole framework, from modelling to analytics.

The framework focuses mainly on the state of Victoria, especially in the modelling and validation parts. However, by adjusting it to take account of specific features of land administration, the framework can be applied to other jurisdictions to support the management of land and property information in other urban areas. For example, the IFC schema could be extended to include the required information for legal title systems by country. In addition, 3D data validation rules should respond to the land registry service of a country. The implementation of the framework needs to take national legislation into consideration in order to achieve cross-national collaboration and spatial information interoperability at federal, state and local government levels.

From a technical perspective, this framework shows limitations in its practical implementation. Firstly, the extension or the integration of 3D data schemas needs to be discussed in order to accommodate the physical, legal, indoor and outdoor information of land and property required for analysis purposes in specific jurisdictions. In addition, generic and jurisdictionspecific validation rules for 3D information of land and property should be established. The rule management system needs to be flexible enough to perform the validation rule-checking for a variety of analytical purposes. Lastly, an open platform based on open standards for 3D data models needs to be developed to support the federation, validation and analytics of the framework. The validation management system should be connected to this platform. Future work will focus on the limitations of this research as outlined here. 


\section{Conclusion}

Land and property information associated with the legal ownership of properties in urban built environments cannot currently be captured appropriately and utilized as a source of knowledge to support land and property decision-making at government, business and community levels. The development of a 3D spatial data framework has high potential to alleviate the traditional fragmented communication and management of the legal extent of urban land and property. However, this movement towards a 3D data environment reveals the lack of a comprehensive, holistic approach, and a limited knowledge base to establish a 3D digital data infrastructure for modernizing land and property practices. Here, we have proposed a 3D spatial data framework, explored its main components, and highlighted its potential for creating better and more effective urban planning and management. A 3D digital land and property infrastructure will support collaboration and coordination in sustainable urban development and reduce costs associated with data duplication, potentially saving millions of dollars per annum.

\section{References}

Acil Allen Consulting. (2017). 3D QLD Road Map Preliminary Findings - Interim Report Addressing Part A. Atazadeh, B., Kalantari, M., Rajabifard, A., Ho, S., \& Champion, T. (2017). Extending a BIM-based data model to support 3D digital management of complex ownership spaces. International Journal of Geographical Information Science, 31(3), 499-522.

Atazadeh, B., Rajabifard, A., \& Kalantari, M. (2017). Assessing performance of three BIM-based views of buildings for communication and management of vertically stratified legal interests. ISPRS International Journal of Geo-Information, 6(7), 198.

Atazadeh, B., Rajabifard, A., Kalantari, M., \& Shin, J. (2018). A BIM-Driven Approach to Managing Common Properties within MultiOwned Developments. In 6th International FIG 3D Cadastre Workshop 2-4 October 2018, Delft, The Netherlands.

Drobež, P., Fras, M. K., Ferlan, M., \& Lisec, A. (2017). Transition from 2D to 3D real property cadastre: The case of the Slovenian cadastre. Computers, Environment and Urban Systems, 62, 125-135.

Ho, S., Rajabifard, A., \& Kalantari, M. (2015). Invisible'constraints on 3D innovation in land administration: A case study on the city of Melbourne. Land Use Policy, 42, 412-425.

Karki, S., Thompson, R., \& McDougall, K. (2010). Data validation in 3D cadastre. In Developments in 3D geo-information sciences (pp. 92-122). Springer.

Kazar, M., Kothuri, R., Van Oosterom, P., \& Ravada, S. (2008). On valid and invalid three-dimensional geometries. In Advances in 3D geoinformation systems (pp. 19-46). Springer.

Rajabifard, A., Atazadeh, B., \& Kalantari, M. (2018). A critical evaluation of 3D spatial information models for managing legal arrangements of multi-owned developments in Victoria, Australia. International Journal of Geographical Information Science, 32(10), 2098-2122.

Rajabifard, A., Williamson, I., Marwick, B., Kalantari, M., Ho, S., Shojaei, D., Atazadeh, B., Amirebrahimi, S., \& Jamshidi, A. (2014). 3D-cadastre, a multifaceted challenge. In FIG Congress, Kuala Lumpur, Malaysia, 16 - 21 June 2014 (pp. 1-17).

Rönsdorff, C., Wilson, D., \& Stoter, J. E. (2014). Integration of land administration domain model with CityGML for 3D Cadastre. In Proceedings 4th International FIG Workshop on 3D Cadastres, 9-11 November 2014, Dubai, United Arab Emirates (pp. 313-322).

Shin, J., Rajabifard, A., Kalantari, M., \& Atazadeh, B. (2019). BIM-based Approach for Preaction Resolution of Disputes over Common Property Management in Multi-owned Developments. In International Congress and Conferences on Computational Design and Engineering (pp. 330-337). 
Shojaei, D., Olfat, H., Faundez, Q., Kalantari, M., Rajabifard, A., \& Briffa, M. (2017). Geometrical data validation in 3D digital cadastre - A case study for Victoria, Australia. Land Use Policy, 68, 638-648.

Stoter, J., Vosselman, G., Goos, J., Zlatanova, S., Verbree, E., Klooster, R., \& Reuvers, M. (2011). Towards a national 3D spatial data infrastructure: case of the Netherlands. PhotogrammetrieFernerkundung-Geoinformation, 2011(6), 405-420.

Thompson, J., \& Van Oosterom, M. (2012). Validity of mixed 2D and 3D cadastral parcels in the land administration domain model. In 3rd International FIG Workshop on 3D Cadastres: Developments and practices, Shenzhen, China, 25-26 October 2012 (pp. 325-344).

Tsiliakou, E., Labropoulos, T., \& Dimopoulou, E. (2013). Transforming 2D cadastral data into a dynamic smart 3D model. In International Archives of the Photogrammetry, Remote Sensing and Spatial Information Sciences(ISPRS) 8th 3D GeoInfo conference and WG II/2 workshop, Istanbul, Turkey, 27 - 29 November 2013 (pp. 105-111).

Volk, R., Stengel, J., \& Schultmann, F. (2014). Building Information Modeling (BIM) for existing buildings - Literature review and future needs. Automation in Construction, 38, 109-127.

Zhu, Q., Hu, M., Zhang, Y., \& Du, Z. (2009). Research and practice in three-dimensional city modeling. Geo-Spatial Information Science, 12(1), 18-24. 